\title{
PSYCHOLOGICAL DEPRESSION AND ANXIETY AMONG CANCER PATIENTS IN JORDAN
}

\author{
Mr. Eid Ahmad Al-Naeem Shkour \\ PhD Scholar, Department of Psychology, Aligarh Muslim University \\ Prof. (Dr.) Asma Parveen \\ Chairperson, Department of Psychology, Aligarh Muslim University
}

\begin{abstract}
This study was focused on the importance of depression and anxiety that a cancer patient in Jordan suffers from and its impact on his/her psychological and physical conditions are that they help in detecting depression in those who have it and it draws attention to the need to give more care to the psychological aspect of this sample from the perspectives of healthcare officials, psychologists and even the public, in order to provide solidarity and necessary support for this category of patients to help them adapt to the disease and cope with it.

The study also confirmed that cancer is mostly one of the grave diseases that affects the life of patients and causes depression and anxiety in them. For this, it needs official and popular efforts to unite to control or at least limit its spread.
\end{abstract}

\section{INTRODUCTION}

Depression and anxiety are the serious psychological widespread illness around the globe. They are significant illnesses that have clinical presentation and diagnostic criteria. They are wide range of symptoms that significantly hinder the individual from performing his usual activities and duties. Depression and anxiety cause many emotional and physical problems and affect the way of thinking and acting. They can be the usual mood fluctuations, in reaction to a situation we encounter in our lives that triggers sorrow and grief; such as losing a friend or incurring a financial loss. They may sometimes accompany any physical disease due to the impact of body over self. Depression, in this case, is minor, resulting from the condition of the patient with a physical disease, such as cancer. This patient with cancer may interact with this disease through feeling sad 
Journal of Advance Research in Science and Social Science (JARSSC)

Official Publication of Indian Mental Health \& Research Centre

DOI: $10.46523 /$ jarssc.04.02.03

Multidisciplinary, Open Access
ISSN: $2582-2004$

Volume 04, Issue 02

and distressed, as he/she undergoes many psychological effects and fluctuations, as concluded by many studies, which proved that the diagnosis of cancer is the most important factor in causing those psychological effects. The radical changes in lifestyle, fear of death, changes in physical appearance, change in self-perception and change in social status and financial and functional considerations are all very important matters for any cancer patient, as well. Feeling of sorrow and grief is normal during this crisis. When they discover the disease, the majority of patients with cancer respond with denial, rejection, despair. They may also suffer from sleep difficulties, loss of appetite and worried thinking of the future. All these may be indicators of depression (Qadouri \& Karama, 2014).

Cancer is one of the chronic diseases that affect the life of the patient. Once diagnosed with cancer, the patient becomes depressed and desperate to a great extent that affects his/her psychological status and hinders him/her from performing his/her everyday-life functions and enjoying life; in addition to the cost of treatment, the continuous effort to continue treatment for several years and the suffering and pain the patient undergoes; all these matters weaken his/her resistance to the disease. When the patient faces pain with optimism and hope of recovering, his/her psychological power decreases. Evidence, studies and researches indicate that strengthening the cancer patient's hope of living helps him/her enhances life factors and stimulates power and vitality, and that the increase of hope reflects in an optimistic outlook based on dispelling despair, depression and frustration that increase the severity and cruelty of pain.

The costs of healthcare for this serious disease in the United States in 2010 are estimated to be about 124.57 Dollar. These costs are expected to increase in the year 2020 to be 157.77 Dollar. This disease is a major burden on the budgets of developed and developing countries (Mariotto et al., 2011).

Cancer is a very serious disease that not only affects and threatens the patient's life, but also affects his/her physical and mental health. The diagnosis of the disease cause distress for the patient, stress, and pain for his family and people around him (Jadoon et al., 2010). Cicely Saunders explained that pain which the cancer patient goes through affects a group of dimensions (physical, psychological, social and spiritual) that are termed "Total Pain" (Shute, 2013). Life of 
the cancer patient has not been as before. He/she has become unable to continue his/her life as it was before the disease because of the emergence of some problems in all aspects of both his/her family life and his/her social life, which lead to a decline in the quality of life both during the diagnostic process and during the treatment and follow-up (Pereira, et al., 2012). Hong \& Tian (2014) reported in a study within the European Society of Oncology that the prevalence of depression among patients with cancer reached (58\%), while the rate of anxiety is estimated to be between (15\%-28\%). The experience of the disease can generate high levels of stress that affect the patient's life, as this disease is considered the disease of death.

\section{THE SCOPE OF STUDY}

Review of literature reveals that more research is needed to prevent and treat co-morbid depression and anxiety among people with cancer and that it requires greater clinical priority. There is a need to examine the factors that may contribute to the development of cmmon mental disorders among people with cancer; the prevalence of depression and anxiety; and potential care and treatment options. Numerous individual, psychological, social and contextual factors potentially contribute to the development of depression and anxiety among people with cancer, as well as characteristics related to the cancer and treatment received. Compared to the general population, the prevalence of depression and anxiety is often found to be higher among people with cancer, but estimates vary due to several factors, such as the treatment setting, type of cancer and time since diagnosis. Overall, there is a lack of high-quality studies into the mental health of people with cancer following treatment and among long-term survivors, particularly for the less prevalent cancer types and younger people. Studies that focus on prevention is minimal and research covering low- and middle-income populations is limited Niedzwiedz et. al. (2019).

Over the past decade, cancer care in Jordan has witnessed remarkable improvement through access to advanced diagnostics and therapeutics (Abdel-Razeq, Attiga, and Mansour, 2010). However, there is least control over the prevalence of psychological problems such as anxiety and depression of cancer patients because of lack of effective coping strategies. Therapeutic measures available to cope with anxiety and depression are expensive and time consuming and require supervisory care. The most important factor is that majority of cancer patients are not aware they 
Journal of Advance Research in Science and Social Science (JARSSC)

Official Publication of Indian Mental Health \& Research Centre

DOI: $10.46523 /$ jarssc.04.02.03

Multidisciplinary, Open Access
ISSN: 2582-2004

Volume 04, Issue 02

also have become psychological patient particularly patients belonging to low and middle-income class. In the present investigations efforts will be made to develop and evaluate the effectiveness of coping strategies to manage anxiety and depression with the help of religion and non-religionbased attention-shift strategies. These strategies are less time consuming and could be used without supervisory care that's why cost will be near to zero.

\section{OBJECTIVES}

This study aimed to identify:

1. The levels of depression and anxiety that a cancer patient in Jordan suffers from and their impact on his/her psychological and physical condition.

2. Whether there are variances in the levels of depression and anxiety that a cancer patient in Jordan suffers from and their impact on his/her psychological and physical condition, caused by the personal variables of the patient (Gender, Age and Type of Treatment).

\section{DEPRESSION AND ANXIETY: CAUSES}

Studies which were done at the cancer centre in Jordan on cancer patients releaved that most of them receive chemotherapy by 56 percent and surgery by 35 percent, which increase the risk of depression and anxiety.

The use of nausea and vomiting medications caused by chemotherapy is also one of the main reasons of depression and anxiety among patients with cancer. In other words, dangerous diseases like cancer might lead to depression and anxiety.

\section{SYMPTOMS OF DEPRESSION AND ANXIETY}

The main symptoms of depression and anxiety that appear in cancer patients are as the following:

- Loss of desire to do daily activities.

- Crying without reasons.

- Feeling of weakness.

- Repeated attempts to commit suicide. 
- Constant sleep disturbances.

- Complaining about headache and back pain continuously.

- Poor concentration.

- Always nervous even for the simplest things.

- Wish Death.

- Decreased libido.

- Weigh gain or loss unintentionally.

- Quandary in taking decision.

- Low energy and fatigue.

- Thinking a lot about death.

\section{TREATMENT FOR DEPRESSION AND ANXIETY}

In 2018, the US Food and Drug Administration approved the use of psilocybin, extracted from mushrooms, in the treatment of many mental and psychological diseases. Psilocybin is found in about 200 species of mushrooms, which have long been described as "magic mushrooms." Because of its compounds that are able to treat depression and overcome life's stresses.

In continuation of the magical state associated with psilocybin, a study published in Psychopharmacology, today, Tuesday, January 28, revealed that taking a single dose of it - in conjunction with psychotherapy sessions - helps improve the psychological state of cancer patients.

And the study, conducted by American researchers, adds that "the effect of this anesthetic found in mushrooms may last for about five years in cases of depression caused by the fear of death, which afflict cancer patients," noting that "patients receiving a single dose of it was associated with a decrease in Persistent levels of anxiety, depression, hopelessness, frustration, and fear of death at each of the follow-up points were performed the first time three years after the patient received that dose, and the second time four and a half years after taking the drug.

Stephen Ross, assistant professor at New York University Langone Health, and co-author of the study, told Al-Alam: There is an urgent need for an alternative way to treat anxiety and depression 
related to cancer, for example Mindfulness Based Cognitive Therapy (MBCT) is effective treatment in Anxiety (Kazmi et al., 2020). Statistics from several sources indicate the possibility of 40 percent of the world's people suffering from cancer. On the other hand, one third of these people suffer from depression and anxiety because of their diseases.

"These conditions are associated with poorer quality of life, increased suicide rates, and decreased survival," Ross adds. "Traditional drug therapies, such as antidepressants, may be effective for less than half of cancer patients, and do not work better than medication." In addition, these drugs may not have any effect on the clearance of these disorders, which often accompany cancer diagnoses and are associated with an accelerated death wish and increased suicidal ideation."

This study is an extension of a previous study conducted in 2016 on 29 cancer patients. Each received nine psychotherapy sessions, plus one dose of psilocybin, or a dose of a placebo called niacin, can produce a slow physical sensation that mimics the experience of psilocybin.

Not only did the results of the study confirm a continued improvement in anxiety and depression in about 60 to $80 \%$ of the participants, but they also confirmed an improvement in the quality of life and a modification of patients' attitudes towards thinking about death.

If the first study attempted to measure the improvement in the psychological state of patients within six months, the new study aimed to measure this long-term effect through a follow-up to a subset of the research sample that was included in the first study. A total of 16 survivors were contacted from the first study, 15 of whom agreed to take part in the new study for a period ranging from 3.2 to 4.5 years after taking psilocybin.

"In addition to evidence dating back to the 1950s, our results strongly suggest that psilocybin therapy is a promising way to improve the emotional and emotional state of cancer patients," Ross says. late illness.

The results of the new thesis found that between 60 to $80 \%$ of the participants had significant antidepressant and anti-anxiety responses during the follow-up years, and the majority of the participants attributed this to the positive changes that occurred in their lives after trying 
psilocybin therapy, which they described as "one of the most meaningful spirituality in their lives," according to the press release accompanying the study.

"Psilocybin provides a useful tool for enhancing the effectiveness of psychotherapy and ultimately relieving these symptoms," Ross adds. "However, the exact mechanisms by which the drug works are not fully understood, but we believe that the drug can make the brain more flexible and receptive to thoughts and patterns." new thinking.

\section{DEFINITIONS}

Depression: The American National Institute of Mental Health (NIMH) defines depression as a disorder that impacts the whole body, thoughts and mood. It also affects the view of the individual to his own self, to people around him/her and to the events taking place in a way that makes the patient lose his physical, psychological and emotional balance (Hijazi, 2013, p11).

Anxiety: According to Barlow 1988, anxiety is a mood state characterized by marked negative affect and somatic symptoms of tension in which person apprehensively anticipates future danger or mis-fortune. American psychiatric association 1994, explains anxiety as a state of uneasiness and apprehension, as about uncertainties of future.

Cancer: (Hong \& Tian, 2014, p9) defined cancer as an irregular growth of some cells in the body, which makes them multiply, may be invade natural tissue adjacent to it and spread to other places. This growth may occur anywhere in the body and to any cell type. It is an abnormal growth that can be imagined as a parasite that lives on intruding the body and affects both and affects both sexes and all races.

\section{A CHILD WISH}

Someone asked a child with cancer before, what is your wish? She said that cancer gets cancer and dies. Cancer is one of the most severe diseases that afflict humans. It does not differentiate between the old and the young, the rich and the poor. God afflicts with it whomever He wills of his servants, and it is considered as the test of endurance, the test of patience, and finally the test of affliction. 
Journal of Advance Research in Science and Social Science (JARSSC)

Official Publication of Indian Mental Health \& Research Centre

DOI: $10.46523 /$ jarssc.04.02.03

Multidisciplinary, Open Access
ISSN: 2582-2004

Volume 04, Issue 02

\section{CONCLUSION}

The mental health of people living with and beyond cancer in its various types and stages is an important and growing research and clinical priority. Compared to the general population, the prevalence of anxiety and depression is often higher among people with cancer, but estimates vary due to a number of factors, such as the type and stage of cancer. Patients often do not obtain psychological support or treatment. This is likely due to several factors, including lack of awareness and identification of psychiatric symptoms, an absence of support available or offered, lack of evidence around effective treatments, stigma, and patient preference. In particular, we highlight the lack of high-quality research into the mental health of long-term cancer survivors, the potential impact of long-term and late effects of cancer treatment, and the few studies focused on prevention of psychological issues like depression and anxiety in Cancer patients. Further research that includes the psychological impacts of cancer is required, as well as the inclusion of younger people and populations from low- and middle-income countries. Given the increasing numbers of people living with and beyond cancer, this research is of timely importance.

\section{REFERENCES}

Mariotto, Angela B., (2011). "Projections of the cost of cancer care in the United States: 20102020." Journal of the National Cancer Institute 103:2: 117-128.

Hijazi, Sana Abu Nasr (2013). Clinical Psychology - Al-Maseera Publishing and Distribution House - Amman - V.2

Kadouri, Ahlam \& Karamah, Siham (2014). Depression in Women with Cancer, A Field Study at Mohammed Boudiaf Hospital - Ouargla - Unpublished MA Thesis, Kasidi Merbah University Ouargla - Algeria.

American Cancer Society - Anxiety, Fear and Depression, 14/4/2016. Available at: hi pi//www.cancer.org/treatment/treatmentsandsideeffects/emotionalsideeffects/anxietyfeardepression-and-cancer 
Journal of Advance Research in Science and Social Science (JARSSC)

Official Publication of Indian Mental Health \& Research Centre

DOI: $10.46523 /$ jarssc.04.02.03

Multidisciplinary, Open Access
ISSN: 2582-2004

Volume 04, Issue 02

Hong, J.S. \& Tian, J. (2014) - Prevalence of anxiety and depression and their risk factors in Chinese cancer patients - Supportive Care in Cancer - 22 - PP. 453-459. DOI 10.1007/s00520013-1997-V.

Jadoon, N. A., Munir, W., Shahzad, M. A. \& Choudhry, Z. S. (2010) - Assessment of depression and anxiety in adult cancer outpatients: a crosssectional study - Bio Med Central, 10 (594), 14712407. DOI: $10.1186 / 14712407-10-594$.

Pereira, M. G., Figueiredo, A. P. \& Fincham, F. D. (2012). Anxiety, depression, traumatic stress and quality of life in colorectal cancer after different treatments: A study with Portuguese patients and their partners - European Journal of Oncology Nursing - 16 - PP. 227-232.

Shute, C. (2013) - The Challenges of Cancer Pain Assessment and Management - Ulster Med J 82 (1), PP. 40-42.

Elkin, Irene. (1989). "National Institute of Mental Health treatment of depression collaborative research program: General effectiveness of treatments." Archives of general psychiatry 46(11) (1989): 971-982.

Abdel-Razeq, Hikmat, Fadwa Attiga, and Asem Mansour. (2015). "Cancer care in Jordan." Hematology/oncology and stem cell therapy 8(2): 64-70.

Kazmi, Syed Sajid Husain and Zaidi, S. Z. H. and Ali, Mohd, Mindfulness Based Cognitive Therapy during COVID-19 Pandemic (December 3, 2020). Available at SSRN: https://ssrn.com/abstract=3741789 or http://dx.doi.org/10.2139/ssrn.3741789

Barlow, D.H. (1988). Anxiety and its disorders. The nature and treatment of anxiety and panic. New York: Guilford Press. 